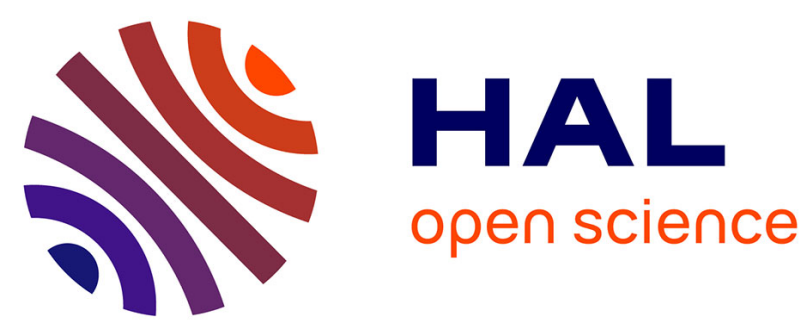

\title{
Effects of Radiofrequency Radiation on Gene Expression: A Study of Gene Expressions of Human Keratinocytes From Different Origins
}

Catherine Martin, Frédéric Percevault, Kate Ryder, Etiam Sani, Jean-Christophe Le Cun, Maxim Zhadobov, Ronan Sauleau, Yves Le Dréan, Denis Habauzit

\section{To cite this version:}

Catherine Martin, Frédéric Percevault, Kate Ryder, Etiam Sani, Jean-Christophe Le Cun, et al.. Effects of Radiofrequency Radiation on Gene Expression: A Study of Gene Expressions of Human Keratinocytes From Different Origins. Bioelectromagnetics, 2020, 41 (7), pp.552-557. 10.1002/bem.22287 . hal-02930148

\author{
HAL Id: hal-02930148 \\ https://hal.science/hal-02930148
}

Submitted on 9 Nov 2020

HAL is a multi-disciplinary open access archive for the deposit and dissemination of scientific research documents, whether they are published or not. The documents may come from teaching and research institutions in France or abroad, or from public or private research centers.
L'archive ouverte pluridisciplinaire HAL, est destinée au dépôt et à la diffusion de documents scientifiques de niveau recherche, publiés ou non, émanant des établissements d'enseignement et de recherche français ou étrangers, des laboratoires publics ou privés. 


\section{Effects of radiofrequency radiation on gene expression: a study of gene expressions of human keratinocytes from different origins}

Catherine Martin ${ }^{1}$, Frederic Percevault ${ }^{1}$, Kate Ryder ${ }^{1}$, Etiam Sani ${ }^{1}$, Jean-Christophe Le Cun ${ }^{2}$, Maxim Zhadobov², Ronan Sauleau², Yves Le Dréan ${ }^{1}$, and Denis Habauzit ${ }^{1 *}$

\footnotetext{
${ }^{1}$ Univ Rennes, Inserm, EHESP, Institut de Recherche en Santé, Environnement et Travail (IRSET) - UMR_S 1085, F-35000 Rennes, France

2 Univ Rennes, CNRS, Institut d’Électronique et de Télécommunication de Rennes (IETR), UMR 6164, F-35000 Rennes, France
}

\section{*Corresponding author:}

Dr Denis Habauzit, Transcription, Environment and Cancer Group, Institute for Research on Environmental and Occupational Health (IRSET), Inserm UMR1085, 9 Avenue du Prof. Léon Bernard, 35043 Rennes Cedex, France. Tel: (+33) 2232350 95; E-mail:

habauzit.denis@gmail.com

Conflict of interest: none

Running title: Effects of MMW radiation on gene expression

Grant sponsor: French National Program for Environmental and Occupational Health, Anses (EST-20162-RF-02) 
Keywords: millimeter waves; $60-\mathrm{GHz}$ band; keratinocytes; gene expression; keratinocyte origins

\section{Introduction}

The answers to questions related to the biological effects of radiofrequency radiation exposure on organisms are pending. In bioelectromagnetic experiments, one of the main difficulties is that the results found in the literature, even those obtained with equivalent models, are poorly reproducible. This poor reproducibility may be due to the use of various biological material and exposure systems, varying exposure durations and, most of the time, varying frequencies. For instance, focusing on the impact of the electromagnetic field on gene expression, we found that the 8 most recent publications used microarrays based on 5 different models (mouse, rat, human, Drosophila, and chicken models); 8 different frequencies, from intermediary frequencies to radiofrequencies; and 3 data processing methods (no statistical tests, simple tests, and false discovery rate (FDR) statistical test) [Andocs et al., 2016; Fragopoulou et al., 2018; Habauzit et al., 2020; Kim et al., 2016; Lamkowski et al., 2018; Manta et al., 2017; Woelders et al., 2017; Yeh et al., 2015]. Together, the differences in these parameters make it difficult not only to compare individual experiments but also to replicate them.

For decades, evaluations of the potential effects of electromagnetic waves have focused on several pathways that could be involved in cancer promotion, such as DNA damage and oxidative stress pathways [Saliev et al., 2019; Vijayalaxmi and Prihoda, 2012]. The research 
performed to date has intensively explored whole-genome gene expression modification under radiofrequency exposure [Leszczynski et al., 2012; Leszczynski, 2014]. In particular, genomic high-throughput approaches have enabled whole-genome gene expression to be screened under both exposure and control conditions, but such approaches have failed to produce clear agreements.

Our group has performed several microarray experiments to evaluate the effects of millimeter waves (MMWs) at approximately $60 \mathrm{GHz}$ on gene expression [Habauzit et al., 2014; Le Quément et al., 2012; Soubere Mahamoud et al., 2016]. We have used microarray approaches with primary cultures of human keratinocytes as the main targets of MMWs. First, we have found that when MMWs are applied alone in athermic conditions and when microarrays are analyzed with a false discovery rate (FDR) filter, the MMWs have no effect on gene expression [Habauzit et al., 2014; Le Quément et al., 2012; Soubere Mahamoud et al., 2016]. However, when MMWs are applied at an incident power density (IPD) of $20 \mathrm{~mW} / \mathrm{cm}^{2}$ (the current International Commission on Non-lonizing Radiation Protection (ICNIRP) upper limit for local exposure of the general public [Ahlbom et al., 1998]) in association with other stressors (heat or metabolic stresses, for instance), the results from the same analysis (with FDR-filtered data) reveal a slight effect of the MMWs on gene expression with 7 and 6 modified genes [Habauzit et al., 2014; Soubere Mahamoud et al., 2016]. Among the modified genes, 3 genes exhibit changes sufficiently reproducible for study: ADAMTS6, IL7R, and NOG. The aim of this study was to evaluate the universality of the expression modifications of these genes in other primary cultures of keratinocytes and a cell line.

\section{Materials and methods}




\section{Cell cultures}

Four cell types were used. The first cell type corresponded to a pool of primary human keratinocytes isolated from 3 neonatal foreskins and was called HEK_3N (Invitrogen, SaintAubin, France). The second cell type, called HEK_1N, consisted of primary human keratinocytes from a single donor of neonatal foreskin (Invitrogen, Saint-Aubin, France). The third primary culture (NHEK_3N) was derived from 3 pools of donated neonatal foreskin (Lonza, Levallois-Perret, France). All primary keratinocytes were cultured and exposed as previously described [Habauzit et al., 2014] and were used when they were between passages 4 and 9. Briefly, cells were cultured onto collagen IV-coated plates (Becton Dickinson, Franklin Lakes, NJ) in supplemented keratinocyte serum-free medium (SFM) (Gibco, Carlsbad, CA) with antibiotics (Invitrogen, Saint-Aubin, France). The derived keratinocyte cell line (HaCaT) was used and maintained in culture in Dulbecco's modified Eagle medium (Gibco/Life Technologies, Saint-Aubin, France) supplemented with $10 \%$ fetal calf serum (FCS), $1 \%$ antibiotics, and 1\% L-glutamine as previously described [Le Quément et al., 2014]. The HaCaT cells were used when they were between passages 5 and 10 .

\section{Exposure system and experimental setup}

The exposure conditions were optimized numerically to maximize the homogeneity of the specific absorption rate (SAR) distribution within the cell monolayer, as detailed previously [Zhadobov et al., 2012]. The IPD was determined numerically and then validated by thermal measurement. The average and peak SAR over the cell monolayer were $594 \mathrm{~W} / \mathrm{kg}$ and 1233 $\mathrm{W} / \mathrm{kg}$, respectively, and corresponded in near-field conditions $(2.5 \mathrm{~cm}$ between the horn antenna and the plate bottom) to an average IPD of $20 \mathrm{~mW} / \mathrm{cm}^{2}$. The exposure system and 
conditions have been detailed previously [Zhadobov et al., 2012]. Briefly, the $2.10^{5}$ cells, in one well of the 6-well plate, were placed in a MEMMERT UNE400 incubator (Memmert, Schwabach, Germany) adapted for electromagnetic exposure. The inside of the incubator was covered with absorbent material (ECCOSORB HR-1/2"-MB, Emerson \& Cuming, Westerlo, Belgium) with a reflectivity below $-20 \mathrm{~dB}$ around $60 \mathrm{GHz}$. This limits the maximum reflections to less than $1 \%$ in respect to the incident field. Due to the properties of MMWs, cell exposures were performed from the bottoms of the wells (Fig. S1). The cells were exposed in the corresponding culture medium supplemented with 10 mM HEPES for primary keratinocyte cultures and 4.6 mM HEPES for HaCaT cells for $3 \mathrm{~h}$. For each experiment $4 \mathrm{ml}$ of medium was used. Note that the volume does not influence either the SAR or the IPD [Orlacchio et al., 2019]. Two exposure conditions (unexposed (Sham) and MMW-exposed (Expo)) were used under the same cell culture conditions. All cells were exposed in the same incubator with the generator on or off. The experiments were replicated between 3 and 6 times.

\section{RNA extraction and $R T-Q P C R$ analysis}

RNA was extracted with a NucleoSpin RNA kit (Macherey-Nagel, Hoerdt, France) and then quantified by a NanoDrop 8000 spectrophotometer (NanoDrop Technology, Cambridge, UK). Five hundred nanograms of RNA was reverse-transcribed with an iScript kit (Bio-Rad, Hercules, CA) according to the supplier's instructions. All primers used are presented in Table 1. Two housekeeping genes (TBP and GAPDH) were used for normalization. Quantitative polymerase chain reaction (QPCR) was performed on a Bio-Rad CFX 384-well apparatus with SYBR Green Supermix (Bio-Rad, Hercules, CA). The results were analyzed using the $\Delta \Delta C T$ method.

Statistical analysis 


\begin{abstract}
Statistical analyses for the comparison of conditions were performed using a one-tailed MannWhitney test on GraphPad Prism software (GraphPad Software, San Diego, CA). A difference at $p$-value $\leq 0.05$ was considered statistically significant.
\end{abstract}

\title{
Results
}

\section{Effect of MMWs on gene expression in keratinocytes}

ADAMTS6, IL7, and NOG gene expression in primary keratinocyte cultures was modified by treatment with growth factors, especially Interleukin-1 (IL1) and Epidermal Growth Factor (EGF). These data confirmed that the expression of these genes was sensitive enough to be modulated, as shown in Figure S2 (supplementary data). For the exposure experiments, 4 cellular models of the exact same cell type, human keratinocytes, were used. Among these cell models, 3 primary cultures were obtained from different donors, and one culture was based on a keratinocyte-derived cell line ( $\mathrm{HaCaT}$ ). Although the cell sources were different, the basal expression of ADAMTS6, IL7R, and NOG was similar in the four keratinocyte models (data not shown). Figure 1 shows the variations in ADAMTS6, IL7R, and NOG expression levels. Three different expression profiles were observed after MMW exposure. The first profile indicated that ADAMTS6 expression was downregulated in HEK_3N cells, with a fold change of 0.5 with associated p-value of 0.057 (Fig. 1A). The second profile did not show any treatment effects, as illustrated by lack of differences in ADAMTS6 expression levels in the sham and expo cells (similarly, no differences were found for IL7R and NOG expression; Fig. 1B-C) in the HEK_1N cells. The third ADAMTS6 profile was characterized by upregulated gene expression in the expo NHEK_3N primary culture cells and the HaCaT cells with associated $p$ - 
value of 0.1 , findings that corresponded to data previously obtained. Together, these three profiles indicate that each biological material shows a specific sensitivity, even when the exposure treatment and conditions are exactly the same. This finding was obtained regardless of whether ADAMTS6 expression was downregulated, not affected, or upregulated. The same expression patterns were also observed for IL7R and NOG (Fig. 1B-C). Among these profiles, no significant differences were found.

\section{Discussion}

In our previous microarray experiments, 3 differentially expressed genes were identified, and one year later, the findings were confirmed by results from independent experiments based on the same cellular model [Habauzit et al., 2014]. These data indicated that MMWs significantly upregulate ADAMTS6, ILR7, and NOG expression. These previously published data [Habauzit et al., 2014] indicated a specific MMW effect independent of a heat-associated MMW response. In this study, we aimed to determine whether the gene regulation observed was specific to the type of cell used or whether it reflected a more general regulation that could be found regardless of the cell type. Therefore, experiments were replicated with three different primary cultures and one cell line. We first tested several growth factors to ensure that these genes could be modulated. These controls validated the RT-QPCR method used to evaluate the MMWs' effects on gene expression. Then, the duplicated experiments in the keratinocyte models showed 3 different expression patterns (downregulation, no effect, and upregulation after both treatments), suggesting that the specific sensitivity observed may depend more on the model used than on the general cell sensitivity to MMW exposure. This 
observation raises two problems of paramount importance in the field of bioelectromagnetism: the reproducibility of the results and impact of the biological model.

Findings of bioelectromagnetic studies are difficult to compare because of the multiplicity of exposure systems, frequencies, treatment durations, models, and technologies required for biological assessment and statistical analysis. Attention is often concentrated on the variations in exposure conditions and wavelengths to explain differences between bioelectromagnetic studies. Consequently, the impact of the biological material is often underestimated. This problem and related problems linked to biological models have started to be illustrated by more general studies in published papers [Lai, 2018; Yakymenko et al., 2016].

The present study shows that the biological model exerts a strong influence on the data obtained, which may at least partly explain the heterogeneity of the reported results in the field. It is important to emphasize that these experiments were conducted at the same frequency $(60.4 \mathrm{GHz})$, in the same exposure system, and for the same exposure duration. In addition, we used 4 cellular models that were all presumed to represent the same biological entity (human keratinocytes) and therefore were expected to react in a similar manner. Surprisingly, we found 3 different expression profiles despite using identical exposure conditions. The statistically significant effect in our first study (based on one primary culture pool) was not reproduced when the biological material was changed, although all the models were composed of keratinocytes (primary cultures sourced from one to three donors randomly obtained from suppliers and a cell line). We conclude that the biological material caused great variability in the cellular response. Two possibilities that are not mutually exclusive may explain such observations. First, it cannot be ruled out that the observed 
variations were reflective of random fluctuations not related to the treatment. Considering their cost, most in vitro studies are repeated a limited number of times. In these cases, the limits of the statistical tests are reached, and false positives can sometimes emerge; for instance, a $p$-value of 0.05 indicates a $5 \%$ probability of the data representing a false positive. Second, the variability in the biological response to exposure could have been associated with the state or history of the biological material. It is well known that heterogeneous gene expression among cellular subclones can be the result of epigenetic modification or somatic mutation. Mutations are very rare events; in contrast, epigenetic modifications are common and relatively more sensitive to the environment. These modifications are essential for cell adaptation and responses to external variations, and they constitute a form of memory that, in turn, may influence how cells respond to environmental stimuli [Park et al., 2014; Veith et al., 2016]. Thus, it is possible that the different expression profiles observed reflect epigenetic modifications specific to the history/state of each cellular model that we used. If sensitivity to the electromagnetic field depends on epigenetic memory, then these results raise questions about inter-individual sensitivity to stimulation in the human population.

Although our past and present results are divergent, it is very likely that the observations were accurate each time. However, they reflected the situation at the moment of the experiment, which depended on the sensitivity and dynamism of the models used. We are aware that this study focused on only three genes and that the results may therefore not be representative of all expected results in bioelectromagnetism studies. Moreover, whether these results can be translated to other radiofrequencies and/or biological models, such as brains, remains unclear. This question is valid, and the uncertainties are illustrated by the many contradictory results described in the literature. Some publications in the field have started to introduce quality criteria [Simkó et al., 2016; Vijayalaxmi, 2016]. Among all the key 
points considered in these publications, validation of the effects in other cell types (different models or equivalent models) should be the main criterion for the identification of clear and reproducible effects of radiofrequency exposure.

In conclusion, our data demonstrate that in the four keratinocyte cell types, 3 different expression patterns (down regulation, upregulation, and no effect) were observed, despite their exposure having been the same in all regards. Additional studies will be necessary to identify the molecular and cellular origins of such variability in exposure sensitivity.

For additional information, see Online Supplementary Materials on the publisher's website.

\section{Legends}

Table Legend

Table 1: List of primers used to validate the identified differentially expressed genes Figure Legends

Fig. 1. ADAMTS6 (A), IL7R (B), and NOG (C) expression in different primary cultures and a cell line. The results are expressed as median, and the error bars represent the interquartile range. In Figure $1 \mathrm{~A}$, the replicate numbers are indicated in brackets. The associated $p$-value is indicated between each comparison.

Fig. S1. Illustration of the exposure system used for all the detailed experiments.

Fig. S2. Gene expression of ADAMTS6 (A), IL7R (B), and NOG (C) under stimulation of Tumor Necrosis Factor (TNF- $\alpha, 50 \mathrm{ng} / \mathrm{ml}$ ), Fibroblast Growth Factor (FGF, $10 \mathrm{ng} / \mathrm{ml}$ ), Leukemia Inhibitory Factor (LIF, 10 $\mathrm{ng} / \mathrm{ml}$ ), Epidermal Growth Factor (EGF, $10 \mathrm{ng} / \mathrm{ml}$ ), Interleukin-1 (IL-1, $50 \mathrm{ng} / \mathrm{ml}$ ), and Transforming Growth Factor (TGF- $\beta, 10 \mathrm{ng} / \mathrm{ml}$ ). The results are the means from two independent experiments \pm SEMs.

\section{References}

Ahlbom A, Bergqvist U, Bernhardt JH, Cesarini JP, Grandolfo M, Hietanen M, Mckinlay AF, Repacholi MH, Sliney DH, Stolwijk JA. 1998. Guidelines for limiting exposure to time- 
varying electric, magnetic, and electromagnetic fields (up to $300 \mathrm{GHz}$ ). Health Phys 74:494-521.

Andocs G, Rehman MU, Zhao Q-L, Tabuchi Y, Kanamori M, Kondo T. 2016. Comparison of biological effects of modulated electro-hyperthermia and conventional heat treatment in human lymphoma U937 cells. Cell Death Discov 2:16039.

Fragopoulou AF, Polyzos A, Papadopoulou M-D, Sansone A, Manta AK, Balafas E, Kostomitsopoulos N, Skouroliakou A, Chatgilialoglu C, Georgakilas A, Stravopodis DJ, Ferreri C, Thanos D, Margaritis LH. 2018. Hippocampal lipidome and transcriptome profile alterations triggered by acute exposure of mice to GSM $1800 \mathrm{MHz}$ mobile phone radiation: An exploratory study. Brain Behav 8:e01001.

Habauzit D, Le Quément C, Zhadobov M, Martin C, Aubry M, Sauleau R, Le Dréan Y. 2014. Transcriptome analysis reveals the contribution of thermal and the specific effects in cellular response to millimeter wave exposure. PLoS ONE 9:e109435.

Habauzit D, Nugue G, Bourbon F, Martin C, Del Vecchio F, Maunoir-Regimbal S, Poyot T, Valente M, Jaoui R, Crouzier D, Le Dréan Y, Debouzy JC. 2020. Evaluation of the effect of chronic $94 \mathrm{GHz}$ exposure on gene expression in the skin of hairless rats in vivo. Radiat Res 193:351-358.

Kim JH, Huh YH, Kim HR. 2016. Induction of autophagy in the striatum and hypothalamus of mice after $835 \mathrm{MHz}$ radiofrequency exposure. PLoS ONE 11:e0153308.

Lai H. 2018. A Summary of Recent Literature (2007-2017) on Neurobiological Effects of Radio Frequency Radiation. In: Markov, M, editor. Mobile Communications and Public Health. Boca Raton, Florida: CRC Press, p. 187-222.

Lamkowski A, Kreitlow M, Radunz J, Willenbockel M, Sabath F, Schuhn W, Stiemer M, Fichte LO, Dudzinski M, Böhmelt S, Ullmann R, Majewski M, Franchini V, Eder S, Rump A, 
Port M, Abend M. 2018. Gene expression analysis in human peripheral blood cells after 900 MHz RF-EMF short-term exposure. Radiat Res 189:529-540.

Le Quément C, Nicolas Nicolaz C, Zhadobov M, Desmots F, Sauleau R, Aubry M, Michel D, Le Dréan Y. 2012. Whole-genome expression analysis in primary human keratinocyte cell cultures exposed to $60 \mathrm{GHz}$ radiation. Bioelectromagnetics 33:147-158.

Le Quément C, Nicolaz CN, Habauzit D, Zhadobov M, Sauleau R, Le Dréan Y. 2014. Impact of 60-GHz millimeter waves and corresponding heat effect on endoplasmic reticulum stress sensor gene expression. Bioelectromagnetics 35:444-451.

Leszczynski D. 2014. Radiation proteomics: a brief overview. Proteomics 14:481-488.

Leszczynski D, de Pomerai D, Koczan D, Stoll D, Franke H, Albar JP. 2012. Five years later: the current status of the use of proteomics and transcriptomics in EMF research. Proteomics 12:2493-2509.

Manta AK, Papadopoulou D, Polyzos AP, Fragopoulou AF, Skouroliakou AS, Thanos D, Stravopodis DJ, Margaritis LH. 2017. Mobile-phone radiation-induced perturbation of gene-expression profiling, redox equilibrium and sporadic-apoptosis control in the ovary of Drosophila melanogaster. Fly (Austin) 11:75-95.

Orlacchio R, Zhadobov M, Alekseev SI, Nikolayev D, Sauleau R, Le Page Y, Le Dréan Y. 2019. Millimeter-Wave Heating in in vitro studies: effect of convection in continuous and pulse-modulated regimes. Bioelectromagnetics 40:553-568.

Park LK, Maione AG, Smith A, Gerami-Naini B, Iyer LK, Mooney DJ, Veves A, Garlick JA. 2014. Genome-wide DNA methylation analysis identifies a metabolic memory profile in patient-derived diabetic foot ulcer fibroblasts. Epigenetics 9:1339-1349.

Saliev T, Begimbetova D, Masoud A-R, Matkarimov B. 2019. Biological effects of non-ionizing electromagnetic fields: two sides of a coin. Prog Biophys Mol Biol 141:25-36. 
Simkó M, Remondini D, Zeni O, Scarfi MR. 2016. Quality matters: systematic analysis of endpoints related to "cellular life" in vitro data of radiofrequency electromagnetic field exposure. Int J Environ Res Public Health 13(7):701.

Soubere Mahamoud Y, Aite M, Martin C, Zhadobov M, Sauleau R, Le Dréan Y, Habauzit D. 2016. Additive effects of millimeter waves and 2-deoxyglucose co-exposure on the human keratinocyte transcriptome. PLoS ONE 11:e0160810.

Veith N, Ziehr H, MacLeod RAF, Reamon-Buettner SM. 2016. Mechanisms underlying epigenetic and transcriptional heterogeneity in Chinese hamster ovary $(\mathrm{CHO})$ cell lines. BMC Biotechnol 16:6.

Vijayalaxmi. 2016. Biological and health effects of radiofrequency fields: good study design and quality publications. Mutat Res 810:6-12.

Vijayalaxmi, Prihoda TJ. 2012. Genetic damage in human cells exposed to non-ionizing radiofrequency fields: a meta-analysis of the data from 88 publications (1990-2011). Mutat Res 749:1-16.

Woelders H, de Wit A, Lourens A, Stockhofe N, Engel B, Hulsegge I, Schokker D, van Heijningen P, Vossen S, Bekers D, Zwamborn P. 2017. Study of potential health effects of electromagnetic fields of telephony and Wi-Fi, using chicken embryo development as animal model. Bioelectromagnetics 38:186-203.

Yakymenko I, Tsybulin O, Sidorik E, Henshel D, Kyrylenko O, Kyrylenko S. 2016. Oxidative mechanisms of biological activity of low-intensity radiofrequency radiation. Electromagn Biol Med 35:186-202.

Yeh C-C, Sun H-L, Huang C-J, Wong C-S, Cherng C-H, Huh BK, Wang J-S, Chien C-C. 2015. Long-term anti-allodynic effect of immediate pulsed radiofrequency modulation 
through down-regulation of insulin-like growth factor 2 in a neuropathic pain model. Int J Mol Sci 16:27156-27170.

Zhadobov M, Sauleau R, Augustine R, Le Quément C, Le Dréan Y, Thouroude D. 2012. Nearfield dosimetry for in vitro exposure of human cells at $60 \mathrm{GHz}$. Bioelectromagnetics $33: 55-64$. 
Table 1: List of primers used to validate the identified differentially expressed genes

\begin{tabular}{|l|l|l|l|}
\hline $\begin{array}{l}\text { Gene } \\
\text { Symbol }\end{array}$ & \multicolumn{1}{|c|}{ Forward } & \multicolumn{1}{c|}{ Reverse } & RefSeq \# \\
\hline ADAMTS6 & ACATCAATCCTCTTCCTCTGGG & TTCAAGTTCTGCAGTCGAGC & NM_197941.4 \\
\hline IL7R & GACGCATGTGAATTTATCCAGCAC & CATACATTGCTGCCGGTTGGAG & NM_002185.5 \\
\hline NOG & AAGCAGCGCCTAAGCAAGAAGC & AATGTCTGCGACCACAGCCACATC & NM_005450.6 \\
\hline GAPDH & TGCACCACCAACTGCTTAGC & GGCATGGACTGTGGTCATGAG & NM_002046 \\
\hline TBP & TGCACAGGAGCCAAGAGTGAA & CACATCACAGCTCCCCACCA & NM_003194 \\
\hline
\end{tabular}




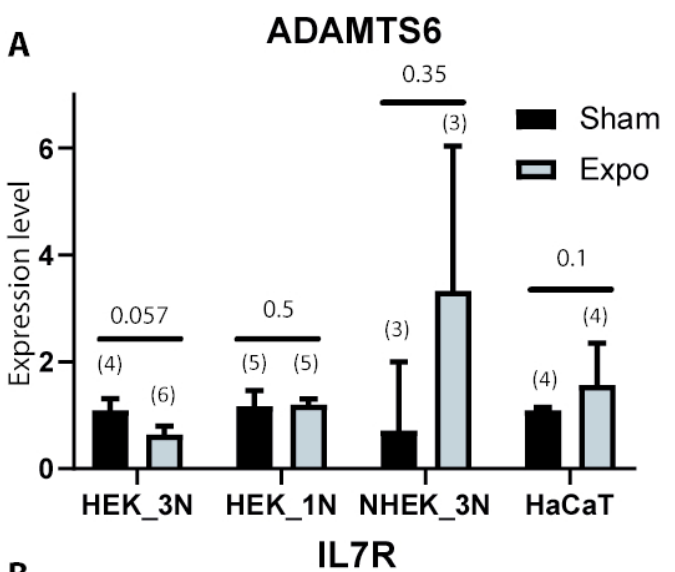

Fig. 1: ADAMTS6 (A), IL7R (B), and NOG (C) expression in different primary cultures and a cell line. The results are expressed as median, and the error bars represent the interquartile range. In Fig. $1 \mathrm{~A}$, the replicate numbers are indicated in brackets. The associated $p$-value is indicated between each comparison. 